On admission to Moorfields Eye Hospital the same day the vision of the right eye was $6 / 6$ and that of the left $6 / 60$. The eye was congested, the pupil oval and partly dilated and only reacting slightly to light. There was a small rupture of the iris sphincter in the superior nasal region. The corneal microscope revealed cells in abundance in the anterior chamber. Four more or less central choroidal tears were present on the temporal side of the disc, as in the figure. The fovea lay nearly mid-way between the second and third. There was some vitreous haemorrhage, no detachment of retina visible, some commotio retinae was evident in the inferior nasal region towards the periphery.

The congestion subsided fairly rapidly. The vitreous cleared completely, the macula showed delicate radiating folds as indicated in modification of the retinal light reflex.

On May 22, 1940, the vision of the left eye with +0.25 cyl., $90^{\circ}$, was $6 / 12$. The patient at this time had no discomfort in his eye and was ready to return to work.

The chart representing scotomata as taken with a $3 / 1000$ white object on May 22, 1940, on Bjerrum screen shows the blind spot somewhat above the normal position, no doubt owing to tilting of the head at the time of examination. The scotoma nearest to the blind spot extending between $2^{\circ}$ and $8^{\circ}$ presumably includes the area of the two nearest choroidal ruptures. The scotoma in the temporal field was not well defined with an object of 3 millimetres diameter and is indicated approximately.

\title{
A CASE OF EXFOLIATION OF THE LENS CAPSULE WITH THE PATHOLOGICAL REPORT
}

BY

\section{Alexander Garrow and I. C. Michaelson \\ GLASGOW}

\section{Clinical Note. A.G.}

THE patient, a robust and healthy looking man, age 69 years, was seen for the first time on March 15, 1938, complaining of defective vision of the right eye of one year's duration. This was found to be due to detachment of the retina and an intra-ocular tumour was diagnosed as the cause of it. The eye was removed on April 6 and the growth was found to be a melanotic sarcoma of the choroid.

For the better examination of the fundus a mydriatic was used in the right eye. The slit-lamp revealed well marked exfoliation of the lens capsule. There was a central film with curled and 
frayed edges and a coarse grained peripheral film also curled over in parts. There was no intermediate film and no exfoliated particles were seen adherent to the pupillary margin of the iris or elsewhere.

The left eye, also, showed a well marked central film of exfoliation but the peripheral parts of the capsule were not examined because a mydriatic was not used in this eye. In this eye, also, no particles of exfoliated capsule were seen on the iris or elsewhere. The size of this pupil was $2.5 \mathrm{~mm}$.

In both eyes there were some opacities in the equatorial region of the lenses. The patient was well preserved and looked younger than his years. The only disability was extreme deafness which dated from measles in childhood and was thought to have been aggravated by his work in a shipyard. The visual acuity of the left eye was 6/9 and there were no signs of glaucoma.

The cataract in this eye continued to develop and has been extracted. Healing was uneventful.

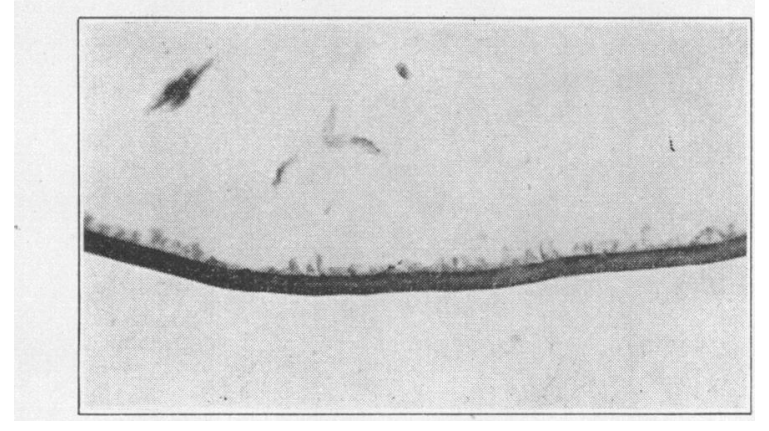

Fig. 1.

Peeling of the more superficial layers of the capsule, whose thickness is left without any gross change.

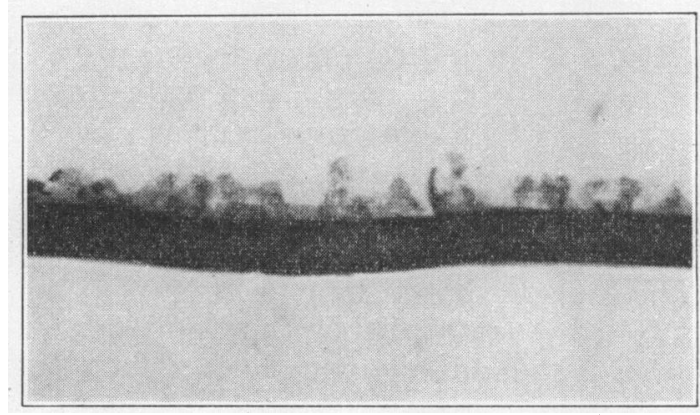

FIG. 2. (See Fig. 1) 


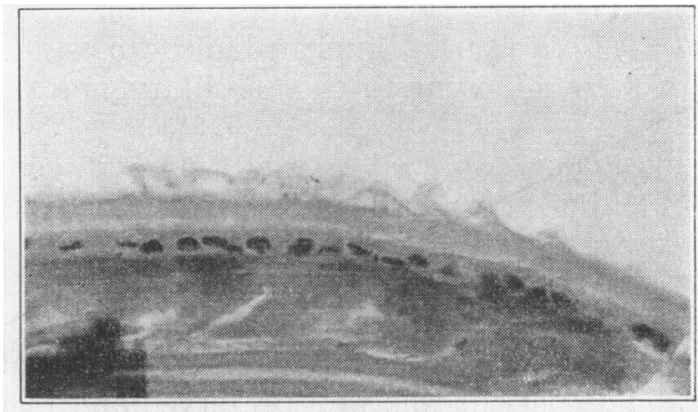

Fig. 3.

Fine strands peeling from the capsule surface.

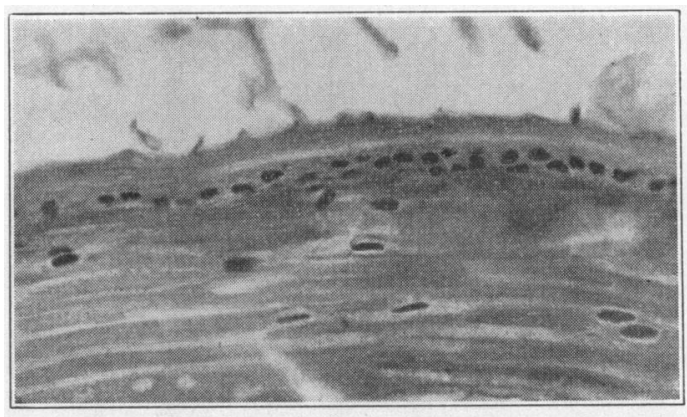

FIG. 4.

Wavy irregularity on surface of capsule. Note irregularity of capsular epithelium.

Observations here and on the Continent indicate the varying frequency of exfoliation of the lens capsule in glaucoma according to the different observers, ${ }^{1}$ but, as in this case, it is found in conditions other than glaucoma. Its relation to and significance in the latter disease have not yet been cleared up. It is probable that the exfoliation is not related to glaucoma in the way of cause or effect but that it is an indication of degenerative changes, ${ }^{2}$ but it does undoubtedly occur most frequently in that form of degenerative change which expresses itself as glaucoma.

\section{Pathological Report. I.C.M.}

The lens was embedded in paraffin and stained with haemalum and eosin. The capsule shows some peeling of its most superficial layers. This is irregular in distribution and present only in the anterior capsule. The tufted appearance which results consists of long thin strands of tissue and of short pointed projections representing the crests of undulations on the surface of the lens 
capsule. These changes can be noted in the micro-photographs. At no place could the marked thinning of the capsule or the feltwork appearance of the tissue described by Vogt be made out. The subcapsular epithelium appears normal but in one place it is duplicated. No debris of detached capsule could be recognised in the angle of the anterior chamber. $\mathrm{Vogt}^{3}$ described five cases which he had the opportunity of examining anatomically. In these he described the separation of the anterior fibres as being somewhat similar to the normal passage of the zonule from the lens capsule, except that it is more axial and in the opposite direction. Open feltwork appearance, peeling and degeneration were the apparently progressive changes noted by him.

The changes now described and illustrated are essentially the same as those recorded by Vogt and our case is of some interest as being the first to be described pathologically from this country.

The microphotographs were lent to Mr. Harrison Butler and figure in his Presidential Address at the Congress of the Ophthalmological Society of the United Kingdom on April 20, 1939.4

We express our thanks to the President and Council of the Ophthalmological Society of the United Kingdom for the use of the blocks of the microphotographs.

\section{REPERENCES}

1. Garkow, AleXander.-Brit. Jl. of Ophthal., Vol. XXII, pp. 216-217, 1938.

2. I Ibid., p. 222.

3. Vogt, A.-Spaltlampienmikroskopic, Berlin, 1930.

4. Butler, T. Harrison.-Trans. Ophthal. Soc. U.K., Vol. LIX, Part 1, pp. $37-38,1930$.

\section{SOME CASES OF TRAUMATIC MYOPIA*}

BY

\section{O. GAYER MORgan}

LONDON

AFTER direct trauma to the eye, one not infrequently notes the development of myopia with or without actual damage to the lens itself.

According to the intensity of the injury one can distinguish four different types:-

1. Those due to spasm of the ciliary muscle associated either with spasm of the sphincter pupillae, or with traumatic mydriasis.

\footnotetext{
* Read at the meeting of the British Medical Association in Aberdeen, 1939.
} 